\title{
Influence of Powder and Paste on SCC Using Recycled Concrete Aggregate
}

\author{
S. Girish
}

\begin{abstract}
The use of recycled concrete aggregate is an important issue for preserving the natural resources, protecting the environment, saving of energy and for sustainable development. In this study, a unique simple mixture proportioning method was successfully adopted for developing SCC based on the absolute volume concept, starting with a volume of paste with maximum aggregate size of $20 \mathrm{~mm}$. The method involved very few trials with different types of aggregate that can be advantageously used in field practice. The volume of paste chosen was 0.38 to 0.43 fraction of the total mix. Natural crushed angular granite and recycled demolished concrete waste were used as aggregate for making SCC with fly ash as filler. SCC and vibrated normal concrete mixes were made for varying cement contents of $300 \mathrm{~kg} / \mathrm{m}^{3}$ to $450 \mathrm{~kg} / \mathrm{m}^{3}$ and for a constant water content of $185 \mathrm{l} / \mathrm{m}^{3}$. Cubes of $150 \mathrm{~mm}$ size were cast and tested for compressive strength at different ages of 7, 28 and 60 days. The results indicate that higher paste content not only makes the mix more cohesive with better lubrication of aggregates, but also increases the slump flow (reduces yield stress) and compressive strength. The 28 day compressive strength of SCC with both natural and recycled concrete aggregate showed higher compressive strength than vibrated normal concrete and significant increase at later age, possibly due to pozzolanic activity of the filler material (fly ash). However, the compressive strength of SCC mixes with recycled concrete aggregate has a lower value, when compared with SCC mixes of natural crushed angular granite aggregate at the same age. The study clearly shows the importance of paste in SCC and the advantage of using recycled concrete aggregate with better performance than the vibrated normal concrete with natural crushed aggregate and can go a long way in conserving the natural resources by the use of recycled concrete aggregate for sustainable development.
\end{abstract}

Keywords--- Self Compacting Concrete, Recycled Concrete Aggregate, volume of Paste, Mixture Proportioning, Compressive Strength, Sustainable Development

\section{INTRODUCTION}

$\mathrm{P}$ RESENTLY the construction industry is using more and more natural resources in the backdrop of rapid development of infrastructure for producing aggregate,

S. Girish, Professor, Department of Civil Engineering, B.M.S. College of Engineering, Bangalore, India. E-mail:giris41@yahoo.co.in, girish.civ@bmsce.ac.in

DOI: 10.9756/BIJIEMS.1740 required to make concrete. One of the greatest challenges of the present time is to evolve strategies for the utilization of the large amounts of construction and demolition wastes which has increased considerably over the last few years. The use of recycled aggregate in concrete opens a whole new range of possibilities in the reuse of materials in the building industry. When structures made of concrete are demolished or renovated, concrete recycling is an increasingly common method of utilizing the rubble. The utilization of Recycled Concrete Aggregates (RCA) is a good solution to the problems of excess waste material, provided that the desired quality of the product is reached. Recycling of concrete is a very important issue for saving energy, resources and for environmental protection. One has to be cautious in the use of RCA, since it exhibits different characteristics from natural aggregate.

To overcome the problems associated with compaction and design requirements, Self-Compacting Concrete (SCC) was first developed in Japan to obtain good quality concrete which ensured durable structural concrete without depending on the consolidation equipments and to a lesser extent, on skilled labor [1]. SCC is certainly one of the difficult concretes to design due to the necessity of finding equilibrium between its different properties which depend on distinct mechanisms. Furthermore, the mixture-proportioning process and the resulting fresh properties is complicated by the multiplication of the constituents available in the market; rounded or crushed aggregates with different mineral natures, ordinary Portland or blended cements, a variety of mineral admixtures, different types of Superplasticizer (SP), and sometimes other chemical admixtures like Viscosity Modifying Admixtures (VMA). Moreover, workability requirements of fresh SCC to have greater flowability, higher stability at rest after casting and generally a good filling ability through narrow reinforcement leads to a high volume of powder and paste which can promote a slightly higher shrinkage and creep. In this context a rational optimization process for SCC is obviously needed to deal with all its constituents and its fresh properties thereof, particularly with its powder and paste contents.

Study conducted by Roziere et al., [2] on SCC mixes for different volume of paste (Vp), using limestone filler, showed marginal decrease (about 12\%) in compressive strength as $\mathrm{Vp}$ increased by $57 \%$. The decrease in strength due to increasing $\mathrm{Vp}$ can be attributed to the fact that the aggregates are generally stronger than the paste and decreasing aggregates is likely to reduce the mechanical strength. On the contrary, Zsigovics [3] studied SCC mixes with limestone powder, showed increase in compressive strength with increase in powder or Vp. Pineaud et al., [4] studied SCC mixes using 
limestone filler for different $\mathrm{Vp}$ and concluded that $\mathrm{Vp}$ has only slight effect on the compressive strength, but water binder ratio strongly influenced the compressive strength. Khatib [5] found in his experimental study that a high volume fly ash can be used to produce high strength SCC. Heirman and Vandewalle [6] studied 12 different SCC mixtures with different types of fillers with different sphericality and roundness by keeping the w/c ratio (0.5), water content $(175$ $\left.1 / \mathrm{m}^{3}\right)$, volume of filler/cement ratio $(0.9)$ and fine to coarse aggregate contents constant. They found the compressive strength of SCC is generally higher when compared with normal concrete with the same w/c ratio.

The study conducted by Girish and Arjun [7] on SCC mixes with different paste contents even with a marginal filler material like crushed rock fines, indicate that paste content plays an important role not only on the enhanced flowability of the mix but also on the compressive strength. Study conducted by Kou et. al., [8] for different w/c ratio and recycled aggregate replacement (5 to $100 \%$ of that of normal aggregates) indicates reduction in compressive strength when compared to mixes with normal aggregate. Similar observation was made by the study conducted by Limbachiya et. al., [9] by reporting lower compressive strength with the use of RCA beyond a replacement of $30 \%$. Studies by some of the other researchers $[10,11,12]$ indicate higher absorption, lower compressive strength and difficulty in characterization of recycled aggregates.

The paste or powder component plays an important role in SCC. A minimum $\mathrm{Vp}$ is needed to achieve workability of SCC. Increasing the total powder content or $\mathrm{Vp}$ generally increases the flow ability. Increase in $\mathrm{Vp}$ beyond the minimum can make the mix robust. It provides sufficient cohesion to the fresh concrete. It reduces the intrinsic shear strength of the mix and in addition enhances its smooth flow by overcoming inter-particle friction. However, experience and practical considerations have shown that powder or paste content cannot be increased beyond a level, as this may interfere with the flow characteristics of SCC. SCC needs to have sufficient paste when crushed angular natural aggregates or unfavorable characteristics of RCA are used for achieving good flow ability and also for better coating of the aggregates for enhanced strength.

Outcome of this experimental study brings out the influence of powder and paste in SCC using RCA and the advantage of developing SCC with filler material fly ash following a unique procedure for developing SCC. The use of RCA addresses a very important issue of preserving the natural resources and it is of interest to study the importance of paste content in SCC using RCA since paste is one of the important parameter in the mix design of SCC.

\section{EXPERIMENTAL PROGRAMME}

\subsection{Materials}

Ordinary Portland cement (C 53 grade) conforming to the requirements of IS12269-1987 (ASTM C 150-85A) was used in the study. Fly ash used as filler was obtained from Raichur Thermal Power Station (RTPS), Karnataka, India. It falls in the category of class $\mathrm{F}$ fly ash based on its $\mathrm{CaO}$ content similar to the classification as per ASTM C 618 and also satisfies the requirements of IS 3812-1981. The specific gravity values of the cement and fly ash were 3.15 and 2.20 and the Blaine fineness 296 and $434 \mathrm{~m}^{2} / \mathrm{kg}$ respectively. Natural river sand (zone II) was used as fine aggregate, crushed granite stone was used as normal coarse aggregate (NCA) and crushed demolished concrete aggregates was used as RCA. RCA was procured from a nearby site of the slab portion of the demolished building and crushed using labor to the required size and used after screening. The maximum size of the aggregates used was $20 \mathrm{~mm}$. The bulk specific gravities of the sand, NCA and RCA were 2.66, 2.67 and 2.63 respectively, and their absorption values were $2.22,0.69$ and $4.4 \%$ respectively. Commercially available modified polycarboxylic ether based super plasticizer (SP- Glenium B233) was used as chemical admixture. The product has specific gravity of 1.09 and solid contents not less than $30 \%$ by weight.

\subsection{Mix Proportioning}

Based on the previous study [13] by the author a new mix design method based on absolute volume concept starting with a volume of paste was adopted. First the Vp (mean value 0.41 with a variation of about \pm 0.03 ) is chosen and then the water is chosen. The volume fraction of powder (cement and filler) is obtained by deducting the volume of water from the chosen $\mathrm{Vp}$. In the volume fraction of powder, the relative volumes of cement and filler were changed in order to get concretes of different water to cement ratios. In this manner concretes of varying w/c ratio were obtained without affecting the paste content or the powder ratio. Considering the concrete as one unit, the total volume of aggregate is calculated by deducting the Vp from unit volume. The optimum dosage of SP was obtained by conducting Marsh cone test with the chosen powder and water. It may be noted that since the specific gravity of fly ash was lower than cement, as cement increases the mass of powder also increases when the paste content was constant by volume.

An experimental programme was chosen with three paste contents $(0.38,0.41$ and 0.43$)$ with water content fixed at 185 $1 / \mathrm{m}^{3}$ and the cement contents 300,390 and $450 \mathrm{~kg} / \mathrm{m}^{3}$. Vp is the sum of volume fraction of water and powder. The proportion of coarse aggregate to fine aggregate was taken as 40:60.The w/c ratio ranged from 0.41 to 0.62 covering practically the adopted range in the field. Viscosity modifying admixture has not been employed since all the mixes were made under laboratory- control conditions and as it also influence the flow properties and compressive strength of SCC.

In order to compare the results, Vibrated Normal Concrete (NC) specimens were cast for the same water content and the specimens tested. NC was made by keeping all the constituents of the SCC same except that the filler was replaced by coarse aggregate by absolute volume. Such mixes were workable and did not exhibit any segregation. The cement contents were the same as those considered for SCC mixes and the water content was $185 \mathrm{l} / \mathrm{m}^{3}$. The comparison of 
$\mathrm{NC}$ with SCC has been done in order to understand the influence of filler (Fly ash) content on the strength of SCC.

\subsection{Test Details}

Fresh SCC properties were ascertained by conducting Slump Flow, J-Ring and $\mathrm{V}$ funnel tests as per EFNARC guidelines [14]. A modified mixing procedure was adopted to take the benefit of action of adsorption of molecules of polycarboxylic ether based SP on the cement particles for all the mixes and the modified mixing procedure has been discussed elsewhere by the author [15]. For each SCC mix, cubes of size $150 \mathrm{~mm}$ were cast to determine the compressive strength at the age of 7, 28 and 60 days. For NC $150 \mathrm{~mm}$ cubes were cast and tested at 28 days. The specimens were demoulded 24 hours after casting and were cured under water at $27 \pm 2^{\circ} \mathrm{C}$ until the test age. The tests were conducted as per the codal provisions of IS 516. Figure 1 shows both RCA and NCA used in this study which is highly angular and irregular in shape.

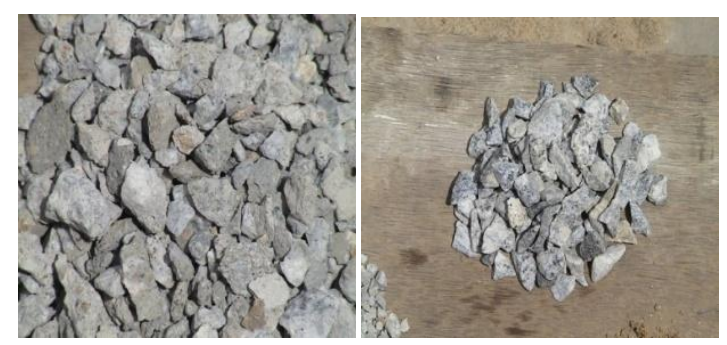

Figure 1: Recycled Concrete Aggregate and Crushed Angular Aggregate

\section{RESULTS AND DISCUSSION}

\subsection{Fresh Properties of SCC}

Table 1 show the fresh property results of SCC mixes with different paste and cement contents with NCA and RCA,

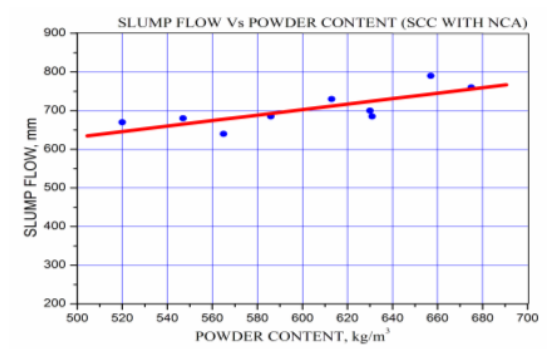

Figure 2 (a): Relation between slump Flow and Powder Content (SCC with NCA)



Figure 2 (b): Relation between Slump Flow and Powder Content (SCC with RCA) but having the same water content of $185 \mathrm{l} / \mathrm{m}^{3}$. All the mixes considered in this study, except for marginally lower values in some mixes, satisfied the EFNARC [14] limits for the fresh properties of SCC. The slump flow and V-funnel tests have been proposed by some researchers as suitable for assessing deformability and viscosity respectively. Slump flow is usually related to yield strength of fresh concrete and V-funnel time to plastic viscosity as Bingham model parameters. Due to low yield stress, slump flow measurement technique is extensively used for evaluating SCC.

Figures 2 (a) and (b) shows the relation between slump flow and powder content of SCC mixes with NCA and RCA respectively. It is significant to note that the slump flow is generally enhanced when powder content is increased for the same Vp even though the water and SP contents are the same, both for NCA and RCA. This indicates a better coating of the surface of the coarse aggregates at higher powder contents or at paste content which causes a decrease in the apparent yield strength of the mix, which in turn increases its shear deformability. This brings out the importance of powder or paste in the flow properties of SCC.

Figure 3 (a) and (b) shows the relation between the slump flow and increase in fly ash content for different $\mathrm{Vp}$ for NCA

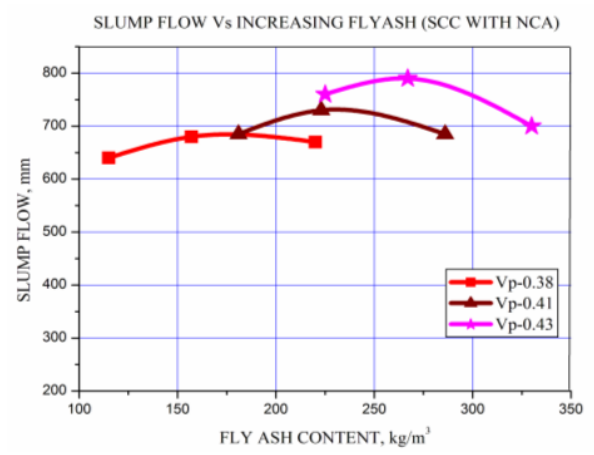

Figure 3 (a): Relation between Slump Flow and Increase in Fly Ash Content for SCC with NCA

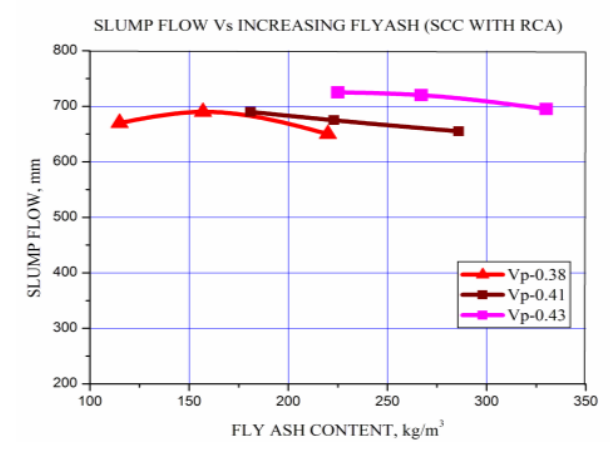

Figure 3 (b): Relation between Slump Flow and Increase in Fly ash content for SCC with RCA

and RCA. When the w/c ratio is constant and when the $\mathrm{Vp}$ is increased, the increase in powder is only due to fly ash content. When the fly ash content is increased, the apparent yield strength of the mix decreases, increasing the shear deformability of SCC. This phenomenon is possibly due to the spherical shape of the fly ash particles which reduces the inter particle friction and also to the greater availability of fly ash 
particles. This is clearly seen in the figure 3 . When the powder content is greater than the optimal value the slump flow decreases indicating the importance and effect of higher powder content. The trend is more pronounced in SCC mixes with NCA.

Figures 4 (a), (b) and (c) show the relationship between the Slump flow, $\mathrm{V}$ zero funnel time and $\mathrm{T}_{50 \mathrm{~cm}}$ verses $\mathrm{Vp}$ for the

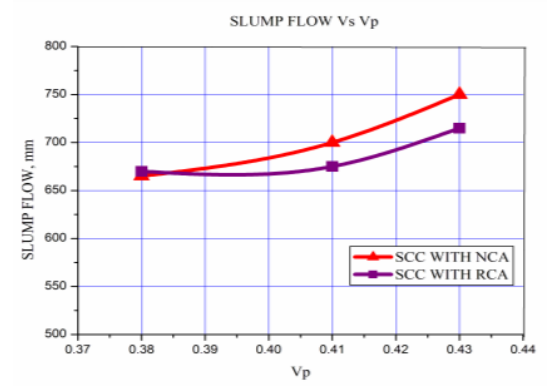

Figure 4 (a): Relation between Slump Flow vs Vp

water content $185 \mathrm{l} / \mathrm{m}^{3}$. Mean values are used for these plots. Figure 4(a) shows that the relationship between Slump flow and $\mathrm{Vp}$, is nearly linear. As the paste content increases, a higher slump flow can be achieved for mixes for both the aggregates. However from figure 4(b) it is seen that the $V$ zero funnel time decreases as $\mathrm{Vp}$ increased for mixes with normal aggregates, but after decrease, increases at a higher value of $\mathrm{Vp}$. This is indicator of possible existence of optimal value, though the results are very few. Researchers associate $\mathrm{V}$ zero funnel time and $\mathrm{T}_{50 \mathrm{~cm}}$ with the plastic viscosity. The trend seen



Figure 4 (b): Relation between V Zero Funnel Time vs Vp with $T_{50 \mathrm{~cm}}$ as seen in figure $4(\mathrm{c})$ indicates that the $T_{50 \mathrm{~cm}}$ increases as $\mathrm{Vp}$ increases. But it may be appreciated that Powers, T.C. [16] had long ago has shown that in fresh concrete two opposing effects are present, one the inter particle friction effect which dominates when fines are less and the other the specific surface effect when the fines are more. Thus there would be an optimum limit for the paste content (or powder content) in a mix beyond which powder should not be increased. Since the water content was constant, the increase in paste is due to increase in powder. The existence of an optimum value of volume of paste is an important factor to be considered in the mix design.

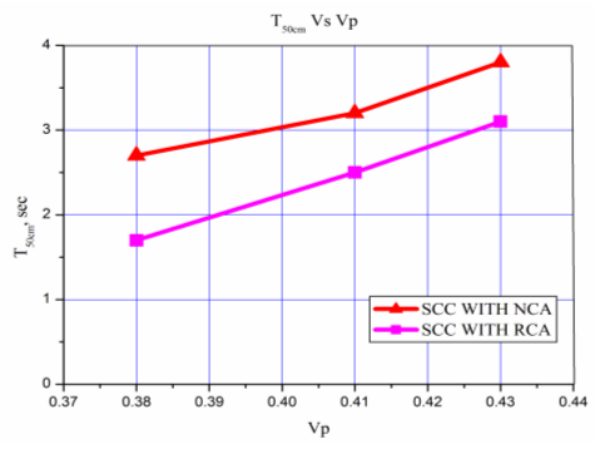

Figure 4 (c): Relation between $\mathrm{T}_{50 \mathrm{~cm}} \mathrm{vs} \mathrm{Vp}$

\subsection{Compressive Strength}

Table II shows the compressive strength of SCC mixes with NCA and RCA tested on $150 \mathrm{~mm}$ cubes. The values are rounded off to the nearest whole number. Figure 5 shows the values of compressive strength of SCC plotted against Vp for SCC made with NCA and RCA with water contents of 185 $1 / \mathrm{m}^{3}$. As can be seen from Figure 5 the 28 day compressive strength increases with the increase in paste content at a constant $\mathrm{w} / \mathrm{c}$ ratio and water content barring one mix. The increase in strength was independent of w/c ratio. This increase in strength with respect to paste was probably due to a better coating of the paste on the aggregates by the fine spherical like fly ash particles, resulting in a better lubricating effect and also probably due to better packing. For all w/c ratios a clear trend is available, that strength increases with $\mathrm{Vp}$, even when w/c and water content were kept constant. It is clearly evident that paste content per se plays a role in the compressive strength of concrete. This needs to be an important consideration in the mix design and the higher paste content can result in higher compressive strength and this can be factored in the mix design, for a given compressive strength. For the mixes the optimal value of paste content in this study seems to be 0.41 , where similar optimality in paste content was noticed in the fresh properties also. The results show that the compressive strength of SCC with RCA is lower than that of SCC with NCA approximately by around $15 \%$ for the material used in this study. Interestingly the performance of SCC with RCA in terms of compressive strength is much superior to that of NC possibly due to higher paste content resulting in better coating and packing of aggregates inspite of unfavorable material characteristics.



Figure 5 (A): Compressive Strength of SCC with NCA for Water Content $185 \mathrm{~L} / \mathrm{M}^{3}$ 


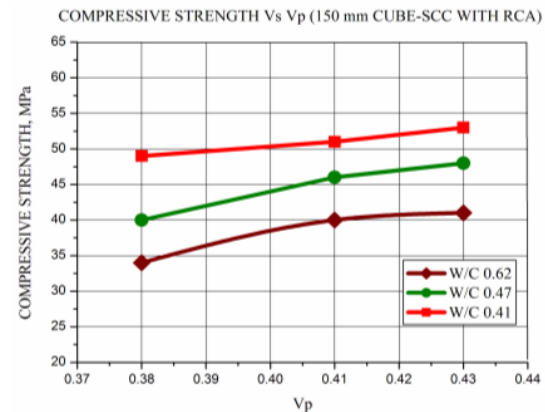

Figure 5 (B): Compressive Strength of SCC with RCA for Water Content $185 \mathrm{~L} / \mathrm{M}^{3}$

\subsection{Compressive Strength verses W/C Ratio}

In Figure 6, 28 day compressive strength values are plotted against w/c ratio for $150 \mathrm{~mm}$ cubes for mixes made with NCA and RCA. For the sake of plotting, the values with the same w/c ratio were averaged for different $\mathrm{Vp}$. The trend is very clear that SCC mixes follows Abram's law with an added feature that the compressive strength is more as the paste content was more for the same w/c ratio. The higher compressive strength due to paste content can be approximately obtained by multiplying the compressive strength of normal concrete (based on the relation between compressive strength verses $w / c$ ratio) with a factor. By this, SCC mixes can be designed starting with a target compressive strength by introducing the modification factors for the chosen paste content.

\subsection{Compressive Strength of SCC and NC}

Figure 7 shows the comparison of compressive strength of $150 \mathrm{~mm}$ cubes at 28 days for NC and SCC with NCA and RCA. It is very clear from the figure that the compressive strength of SCC with RCA is better than NC but lower than that of SCC with NCA. This is possibly due to better densification of microstructure with higher powder or paste content in SCC mixes. Also it may be observed from the values of compressive strength at 60 days the substantial increase in compressive strength. Possibly the continuous hydration of cement has contributed to this increase so also the probable pozzolanic activity of fly ash.

Comparing the two extreme values of Vp of SCC, 0.38 and 0.43 for a water cement ratio of 0.47 it is seen that percentage increase in compressive strength at 28 days is between $67 \%$ to

Table I: Fresh Properties of SCC Mixes (NCA and RCA) with Water Content 185 L/M ${ }^{3}$

\begin{tabular}{|c|c|c|c|c|c|c|c|c|c|c|c|c|c|}
\hline \multirow{3}{*}{$\mathrm{Ce}$} & \multirow{3}{*}{ FA } & \multirow{3}{*}{$\mathrm{TP}$} & \multirow{3}{*}{$\mathrm{Vp}$} & \multicolumn{4}{|c|}{ Slump Flow (SF) } & \multicolumn{4}{|c|}{ V Funnel (Sec) } & \multirow{2}{*}{\multicolumn{2}{|c|}{$\begin{array}{c}\text { J Ring } \\
\text { Diff in Ht } \\
(\mathrm{mm})\end{array}$}} \\
\hline & & & & \multicolumn{2}{|c|}{$\mathrm{SF}(\mathrm{mm})$} & \multicolumn{2}{|c|}{$\mathrm{T}_{50 \mathrm{~cm}} \mathrm{sec}$} & \multicolumn{2}{|c|}{ Vzero min. } & \multicolumn{2}{|c|}{$\mathrm{V}_{5} \min$} & & \\
\hline & & & & NCA & RCA & NCA & RCA & $\mathrm{NCA}$ & RCA & $\begin{array}{c}\mathrm{NC} \\
\mathrm{A}\end{array}$ & RCA & $\mathrm{NCA}$ & RCA \\
\hline 300 & 220 & 520 & \multirow{3}{*}{0.38} & 670 & 650 & 1.8 & 2.1 & 6.1 & 3.8 & 7.5 & 4.2 & 5 & 4 \\
\hline 390 & 157 & 547 & & 680 & 690 & 2.4 & 1.5 & 5.2 & 3.7 & 6.1 & 4.1 & 8 & 3 \\
\hline 450 & 115 & 565 & & 640 & 670 & 4.0 & 1.4 & 8.7 & 4.2 & 11.8 & 4.7 & 3 & 6 \\
\hline \multicolumn{3}{|c|}{ Mean } & & 665 & 670 & 2.7 & 1.7 & 6.7 & 3.9 & & & & \\
\hline 300 & 286 & 586 & \multirow{3}{*}{0.41} & 685 & 655 & 4.2 & 2.3 & 4.3 & 4.2 & 4.5 & 4.9 & 2 & 4 \\
\hline 390 & 223 & 613 & & 730 & 675 & 2.1 & 2.9 & 5.7 & 4.3 & 6.3 & 4.8 & 1 & 2 \\
\hline 450 & 181 & 631 & & 685 & 690 & 3.2 & 2.4 & 4.1 & 4.7 & 5.7 & 5.4 & 8 & 2 \\
\hline \multicolumn{3}{|c|}{ Mean } & & 700 & 675 & 3.2 & 2.5 & 4.7 & 4.4 & & & & \\
\hline 300 & 330 & 630 & \multirow{3}{*}{0.43} & 700 & 695 & 3.1 & 3.1 & 6.0 & 3.8 & 6.9 & 5.6 & 5 & 2 \\
\hline 390 & 267 & 657 & & 790 & 720 & 4.0 & 3.0 & 5.8 & 4.1 & 8.1 & 6.2 & 1 & 1 \\
\hline 450 & 225 & 675 & & 760 & 725 & 4.4 & 3.1 & 5.5 & 6.3 & 6.8 & 7.0 & 9 & 3 \\
\hline \multicolumn{3}{|c|}{ Mean } & & 750 & 715 & 3.8 & 3.1 & 5.8 & 4.7 & & & & \\
\hline
\end{tabular}

Legend: Ce-Cement, $\mathrm{kg} / \mathrm{m}^{3}$, FA-Fly Ash, $\mathrm{kg} / \mathrm{m}^{3}$, TP-Total Powder content, $\mathrm{kg} / \mathrm{m}^{3}$ 
Table II: Compressive Strength of NC and SCC Mixes (NCA and RCA) at Different Ages with Water Content 185 L/M ${ }^{3}$

\begin{tabular}{|c|c|c|c|c|c|c|c|c|c|c|}
\hline \multirow{3}{*}{$\mathrm{Vp}$} & \multirow{3}{*}{$\mathrm{W} / \mathrm{C}$} & \multicolumn{3}{|c|}{$\mathrm{SCC}(\mathrm{NCA})$} & \multicolumn{3}{|c|}{$\mathrm{SCC}(\mathrm{RCA})$} & \multirow[t]{2}{*}{$\mathrm{NC}$} & \multicolumn{2}{|c|}{$\begin{array}{l}\text { Percentage increase in } \\
\text { Compressive strength of SCC } \\
\text { relative to NC }\end{array}$} \\
\hline & & \multicolumn{6}{|c|}{ Compressive Strength (MPa) } & & $\begin{array}{c}\text { SCC } \\
\text { ( RCA) }\end{array}$ & $\begin{array}{c}\text { SCC } \\
(\mathrm{NCA})\end{array}$ \\
\hline & & $7 \mathrm{~d}$ & $28 \mathrm{~d}$ & $28 \mathrm{~d}$ & $7 \mathrm{~d}$ & $28 \mathrm{~d}$ & $60 \mathrm{~d}$ & $28 \mathrm{~d}$ & & \\
\hline \multirow{3}{*}{0.38} & 0.62 & 23 & 40 & 79 & 110 & 34 & 43 & 19 & 79 & 110 \\
\hline & 0.47 & 28 & 46 & 82 & 109 & 40 & 50 & 22 & 82 & 109 \\
\hline & 0.41 & 40 & 51 & 69 & 76 & 49 & 53 & 29 & 69 & 76 \\
\hline \multirow{3}{*}{0.41} & 0.62 & 28 & 45 & 82 & 105 & 40 & 45 & 22 & 82 & 105 \\
\hline & 0.47 & 33 & 52 & 59 & 79 & 46 & 49 & 29 & 59 & 79 \\
\hline & 0.41 & 43 & 60 & 59 & 88 & 51 & 58 & 32 & 59 & 88 \\
\hline \multirow{3}{*}{0.43} & 0.62 & 30 & 48 & 71 & 100 & 41 & 46 & 24 & 71 & 100 \\
\hline & 0.47 & 40 & 50 & 60 & 67 & 48 & 52 & 30 & 60 & 67 \\
\hline & 0.41 & 45 & 62 & 66 & 94 & 53 & 61 & 32 & 66 & 94 \\
\hline
\end{tabular}

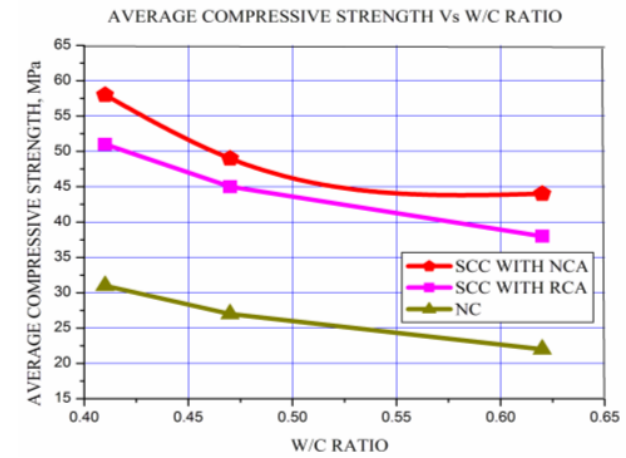

Figure 6: Average Compressive Strength Vs W/C (same W/C Ratio with Different Vp)



Figure 7(a): 28 Day Compressive Strengths of 150mm Cubes of $\mathrm{CNC}$ and $\mathrm{SCC}$ with NCA and RCA $(\mathrm{Vp}=0.38)$

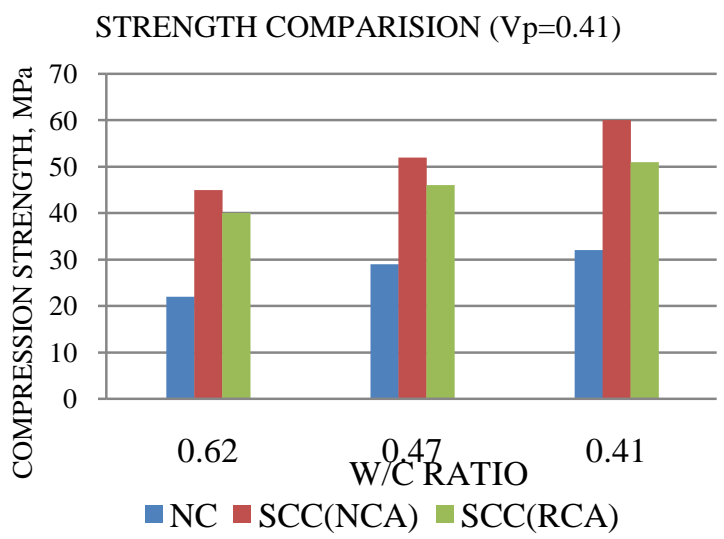

Figure 7(b): 28 Day Compressive Strengths of $150 \mathrm{~mm}$ Cubes of $\mathrm{CNC}$ and SCC with NCA and RCA $(\mathrm{Vp}=0.41)$

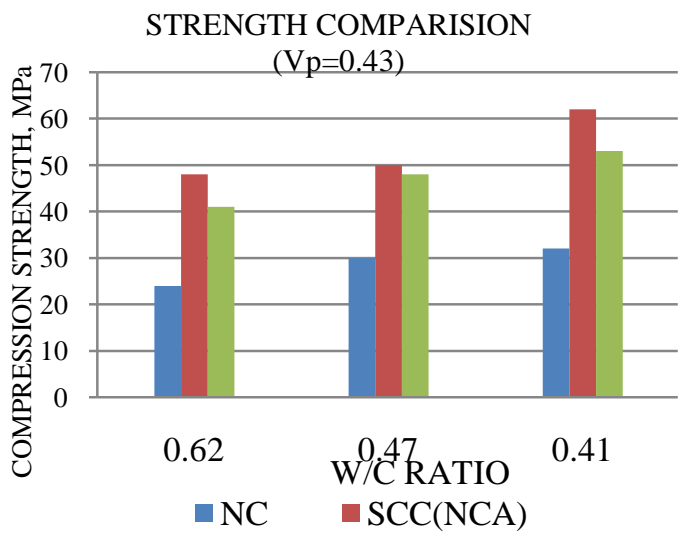

Figure 7(c): 28 Day Compressive Strengths of $150 \mathrm{~mm}$ Cubes of $\mathrm{CNC}$ and $\mathrm{SCC}$ with NCA and RCA $(\mathrm{Vp}=0.43)$ 
$109 \%$ for SCC with NCA and 60 to $82 \%$ for SCC with RCA when compared with NC. In this series of SCC mixes with a constant water content of $185 \mathrm{l} / \mathrm{m}^{3}$, the compressive strength at 28 days are much higher than that of the NC of same water/cement ratio. The experiment also shows that by using fly ash higher compressive strength can be obtained even at lower cement content which would result in economy.

\subsection{Cost Analysis}

It may be pointed out that the ingredients for making SCC and $\mathrm{NC}$ are almost the same. $\mathrm{NC}$ was made by keeping all the constituents of SCC mixes the same, except that the fly ash was replaced by coarse aggregate by equal volume. Fly ash is a waste material and is available for disposal and the cost involved can be neglected except for the transportation cost in some places. However, the additional cost involved for making NC, considering all the ingredients the same, is the replacement cost of coarse aggregate for fly ash which is substantial with the depleting natural resources. Considering the overall cost of making NC and SCC in general, it can be clearly said that the cost of making SCC is in fact less than the cost involved in making $\mathrm{NC}$ not to mention the enormous advantage in terms of increase in compressive strength (further which in turn can make it more economical by reducing the cement content for a particular compressive strength), better micro structure which can improve the durability and additionally the advantage of very good surface finish (can avoid plastering).

Further the use of RCA in place of NCA can make the mix more economical. Since RCA is a waste material and the cost involved in procuring is meager except for crushing and screening at the site using only the labor compared to NCA which is to be procured from the quarry. The study has very clearly brought out not in relative values but in general the economical aspect of using SCC compared to NC with the materials used in this study

\section{CONCLUSION}

The conclusions that have been arrived at from this experimental study on SCC wherein the paste contents have been chosen as primary variables with the use of RCA can be summarized as follows:

The design method based on absolute volume concept starting with paste content is a unique approach and can be successfully employed for achieving SCC. The method is simple and reduces the number of trials. SCC can be fabricated with volume of paste ranging from 0.38 to 0.43 for crushed angular and recycled concrete aggregates of maximum size of $20 \mathrm{~mm}$. As paste content of SCC increases, slump flow which is a measure of the yield strength of fresh SCC is enhanced. It is generally true that as paste content increases slump flow increases but only upto a value. When the paste content is greater than this optimal value, slump flow decreases. This was seen in the case of mixes with volume of paste 0.41. Thus reinforcing the conclusion, that paste (powder) plays an important role in the flow properties of fresh SCC. The compressive strength of SCC increases with paste content both for normal aggregates and recycled aggregates, for the same w/c ratio. The increase can be factored in concrete mix design to economize on cement content. The use of recycled concrete aggregates results in marginal reduction of compressive strength when compared to normal crushed angular aggregates but definitely superior than the vibrated normal concrete. The use of recycled concrete aggregate in SCC is feasible and the performance is better when compared to normal vibrated concrete inspite of difficulty in material characterization.

\section{REFERENCES}

[1] H. Okamura and M. Ouchi, "Self- Compacting Concrete," (invited paper), Journal of Advanced Concrete Technology, Vol. I, No.1, Pp 515, April 2003.

[2] E. Roziere, S. Granger, P.h. Turcry and A. Loukili (2007), "Influence of Paste Volume on Shrinkage Cracking and Fracture Properties of SelfCompacting Concrete," Cement and Concrete Composites, Vol.22, Pp 626-636.

[3] I. Zsigovics, "Effect of Limestone Powder on the Consistency and Compressive Strength of SCC," Proceedings of SCC, Chicago, IL, ACBM, 2005.

[4] A. Pineaud, R. Cabrillac, S. Remond, P. Pimienta and P. Rivillon, "Mechanical Properties of Self-Compacting Concrete- Influence of Composition Parameters," Proceedings of SCC, Chicago, IL, ACBM, 2005.

[5] J.M. Khatib, "Performance of Self-Compacting Concrete Containing Fly Ash," Construction and Building Materials, Vol. 22, Pp. 1963-1971, 2008.

[6] G. Heirman and L. Vandewalle, "The Influence of Fillers on the Properties of Self-Compacting Concrete in Fresh and Hardened State," Proceedings of the 3rd International Symposium on Self-Compacting Concrete, Reykjavik, Iceland, Pp. 606-618, 2003.

[7] S. Girish and H. R. Arjun, "Development of SCC with crusher rock fines as filler", Journal of Structural Engineering, Vol. 38, No 1, Pp 60-66, 2011.

[8] S.C. Kou, C.S. Poon, and D. Chan, "Influence of fly ash as a cement addition on the hardened properties of recycled aggregate Materials and Structures .Vol. 41, Pp 1191-1201, 2008.

[9] M.C. Limbachiya, T. Leelawat and R.K. Dhir, 'Use of recycled concrete aggregate in high-strength concrete', Materials and Structures, Vol.33, Pp. 574-580, 2000.

[10] A.K. Padmini, K. Ramamurthy, and M.S. Mathews, 'Influence of parent concrete on the properties of recycled aggregate concrete',Vol.23, Pp. 829-836, 2009.

[11] K.K. Sagoe-Crentsil, T. Brown, and A.H. Taylor, 'Performance of concrete made with commercially produced coarse recycled concrete aggregate', Cement and Concrete research, Vol. 31, Pp. 707-712, 2001.

[12] J. Zh.Xiao, J. B-Li, and Ch. Zhang, 'On relationship between the mechanical properties of recycled aggregate concrete: an overview', Materials and Structures, Vol. 39, Pp. 655-664, 2006.

[13] S. Girish, Jagadish Vengala and R.V Ranganath, "Volume fractions in self-compacting concrete - A review", Proceedings of the 5th International RILEM Symposium on Self-Compacting Concrete , Ghent, ISBN:978-2-35158-050-9. Pp: 73-79, Vol. 1, 2007.

[14] EFNARC, Specification and Guidelines for Self-Compacting Concrete, UK, ISBN 0953973344, http://www.efnarc.org/, 2002.

[15] S. Girish, R. V. Ranganath and Jagadish Vengala, "Influence of powder and paste on flow properties of SCC" Construction and Building Materials, Vol.24, Pp. 2481-2488, 2010.

[16] C. Powers Treval "Properties of fresh concrete" John Wiley \& Sons, New York, 1968.



Dr.S. Girish has 25 years of experience in teaching, consultancy and research and is presently working as Professor in the Department of Civil Engineering, B.M.S College of Engineering (BMSCE), Bangalore, Karnataka, India. He has worked on Self- compacting concrete for his doctoral work. He has obtained his Doctor of Philosophy (Ph.D.,) from VTU, Belgaum, Karnataka, India in 2010, Master of Engineering (M.E.,) in Structural Engineering from Bangalore University, Bangalore, Karnataka, India in 1988 and Bachelor of Engineering (B.E.,) in Civil Engineering, from National Institute of Engineering (NIE), from Mysore University, Mysore, Karnataka, India, in 1984. 
$\mathrm{He}$ is member in various professional societies including Indian Society for Technical Education, The Indian Concrete Institute, Institution of Engineers (India), Indian Society for Earthquake Technology. He has published research papers in various National and International Journals and in Conferences. His recent publications include "A Step towards Mix Proportioning Guidelines for Pervious Concrete", International Journal of Earth Sciences and Engineering, Volume 04, No 06SPL, October, pp 768-771 in 2011, "Development of SCC with crushed rock fines as filler", Journal of Structural Engineering, Volume 38, No 1, pp 60-66, in 2011 and "Influence of powder and paste on flow properties of SCC", Journal of Construction and Building Materials, (ELSEVIER-Science Direct), Vol. 24, pp 2481-2488 in 2010. He is the recipient of Karnataka State Council for Science and Technology Academic award for the best project in the year 2009 and 2011.

His research interests include Self-compacting concrete, Rheology of concrete, Recycling of concrete waste, Bacterial concrete, Pervious concrete and Geopolymer concrete. (E-mail: giris41@yahoo.co.in, girish.civ@bmsce.ac.in) 